\title{
Photoelectrochemistry and Etching of SiC: a Comparison with Si
}

\author{
J J Kelly ${ }^{1}$, D H van Dorp ${ }^{1}$, J L Weyher ${ }^{2}$
}

1) Condensed Matter and Interfaces, Debye Institute, Utrecht University, Princetonplein 1, 3508 TA Utrecht, The Netherlands

2) Applied Materials Science, Institute for Molecules and Materials, Radboud University

Nijmegen, Toernooiveld 1, 6526 ED Nijmegen, The Netherlands

\begin{abstract}
The anodic electrochemistry and etching of the group IV compound semiconductor $\mathrm{SiC}$ was studied in both $\mathrm{KOH}$ and acidic fluoride solutions. The results for $\mathrm{p}$-type and $\mathrm{n}$ type electrodes are compared with those obtained for the group IV elemental semiconductor $\mathrm{Si}$. We point out a number of interesting applications of this work for $\mathrm{SiC}$ device technology.
\end{abstract}

\section{Introduction}

Silicon has a very rich chemistry in aqueous solution. At high $\mathrm{pH}$ the semiconductor etches chemically [1]. Since this reaction is highly anisotropic, etching reveals crystallographic planes at resist edges. The resulting forms are widely used in microelectromechanical systems (MEMS) [2,3]. Silicon can also be anodically oxidized in alkaline solution and passivated at positive potential [4]. These reactions are observed, not only for the p-type electrode but, surprisingly at comparable current density, also for n-type Si. A combined chemical-electrochemical mechanism has been proposed to explain these results [5]. The anodic passivation of n-type silicon forms the basis for an etch-stop mechanism important for membrane fabrication in MEMS [6, 7]. At low $\mathrm{pH}$, fluoride in solution is required to prevent passivation of Si. In this case the "normal" semiconductor electrochemistry is observed: the p-type electrode can be anodically oxidized in the dark; supra bandgap light is required to oxidize the n-type electrode. In the onset of the anodic (photo)current-potential curve, porous silicon is produced while at 
more positive potential (and for n-type Si at "high" light intensity) soluble oxides are formed and the semiconductor is electropolished [8].

There is a growing need for more robust (opto)electronic devices, capable of operating under extreme conditions. Wide-bandgap, chemically stable semiconductors can meet such a need [9]. The group IV compound semiconductor $\mathrm{SiC}$ is finding application in high-power transistors [10], sensors resistant to high temperature and caustic environment [11] and MEMS devices profiting from the mechanical and chemical properties of the semiconductor $[12,13]$. With such developments there is a renewed interest in the wet chemistry and etching of SiC.

The electrochemistry of $\mathrm{SiC}$ in aqueous solution has not been nearly as well-studied as that of Si. Following the interest in porous $\mathrm{Si}$ in the early nineties, Shor and co workers showed that $\mathrm{SiC}$ can also be made porous by anodic etching in HF solution [14]. The ptype semiconductor dissolves in the dark, while supra-bandgap illumination is required to oxidize the n-type material. Like $\mathrm{Si}, \mathrm{n}$-type $\mathrm{SiC}$ can be made porous at strongly positive potentials in the dark (breakdown conditions) [15]. Okojie and co workers exploited the differences in anodic electrochemistry of n-type and p-type $\mathrm{SiC}$ to fabricate membranes for MEMS applications [16]. A recent study of $\mathrm{n}$-type $\mathrm{SiC}$ in alkaline solution also showed similarities with the electrochemistry of Si [17]. In this paper we report further on both p-type and n-type $\mathrm{SiC}$ in alkaline solution and compare the results with those obtained for $\mathrm{Si}$. We also describe results on $\mathrm{SiC}$ in acidic fluoride solution. For both systems we point out possible uses of (photo)anodic etching for practical device applications.

\section{Experimental}

Single crystal 6H-SiC (n-type) and 4H-SiC wafers (n- and p-type) (0001) were obtained from Cree (United States) and Umicore (Belgium). The n-type wafers were oriented onaxis, nitrogen-doped and had a resistivity of 0.01-0.07 $\Omega . \mathrm{cm}$. The p-type wafer (Cree) was oriented $8^{\circ}$ off-axis, aluminium doped and had a resistivity of $3.86 \Omega . \mathrm{cm}$. All samples used in this study had a Si polar face. For the electrochemical experiments, a circular opening was defined on the samples using a $\mathrm{Si}_{3} \mathrm{~N}_{4}$ mask. The diameter of the opening was $2 \mathrm{~mm}$. Ohmic contacts to the p-type $\mathrm{SiC}$ were made by evaporating a 300 $\mathrm{nm}$ thick layer of $\mathrm{Al} / \mathrm{Ta} / \mathrm{Au}$ on the back side of the wafer. The metallized wafer was 
subsequently annealed at $850{ }^{\circ} \mathrm{C}$ for 10 minutes. The n-type wafers were contacted using a $300 \mathrm{~nm} \mathrm{Ti} / \mathrm{Au}$ layer followed by a 1 second annealing step at $1000^{\circ} \mathrm{C}$. The samples were mounted as a rotating disk electrode (RDE).

Czochralski-grown 4" (100) oriented Si wafers were obtained from Okmetic (Finland). The n-type wafers were phosphorus doped and had a resistivity of 1-10 $\Omega . \mathrm{cm}$. The resistivity of the p-type boron doped wafers was 5-10 $\Omega . \mathrm{cm}$. Ohmic contacts were provided on the backside using a GaIn eutectic. The Si samples $(2 \times 2 \mathrm{~cm})$ were mounted in a Kel-F holder by means of a Viton O-ring.

Electrochemical measurements were performed in a three-electrode cell with a platinum counter electrode and a saturated calomel electrode (SCE) as a reference. A potentiostat (EG\&G Princeton Applied Research, PAR-273-A) computer-controlled by LabVIEW was used to measure the current-potential curves in the dark and under illumination. The curves were recorded at a constant scan rate of $10 \mathrm{mV} / \mathrm{s}$ from negative to positive potential and back. The light source used for the electrochemical experiments was a Hg arc-lamp (500 W) with a power supply (Oriel 66941). UV light from the beam was directed on the sample using a dichroic mirror $(280-400 \mathrm{~nm})$. In order to increase the light intensity a plano convex lens was used to focus the beam on the electrode. In order to prevent heating of the substrate, a heat sink was used. The light intensity was varied with neutral density filters. Before the measurement, the samples were rinsed with acetone.

The etch rate was determined by measuring the etch depth with a surface profiler (Alpha-Step 500) and the surface morphology after etching was examined using a differential interference contrast (DIC) optical microscope (Nicon ECLYPSE ME 600), an atomic force microscope (Digital Instruments Nanoscope IIIa) and a scanning electron microscope (SEM JEOL 6330).

For the electroluminescence experiments a $0.1 \mathrm{M} \mathrm{K}_{2} \mathrm{~S}_{2} \mathrm{O}_{8}, 0.5 \mathrm{M} \mathrm{H}_{2} \mathrm{SO}_{4}$ solution was used. The spectra were recorded with a CCD camera (Acton Research Corporation, Spectra Pro-300i). 


\section{Results and Discussion}

$\underline{\text { High } \mathrm{pH}}$
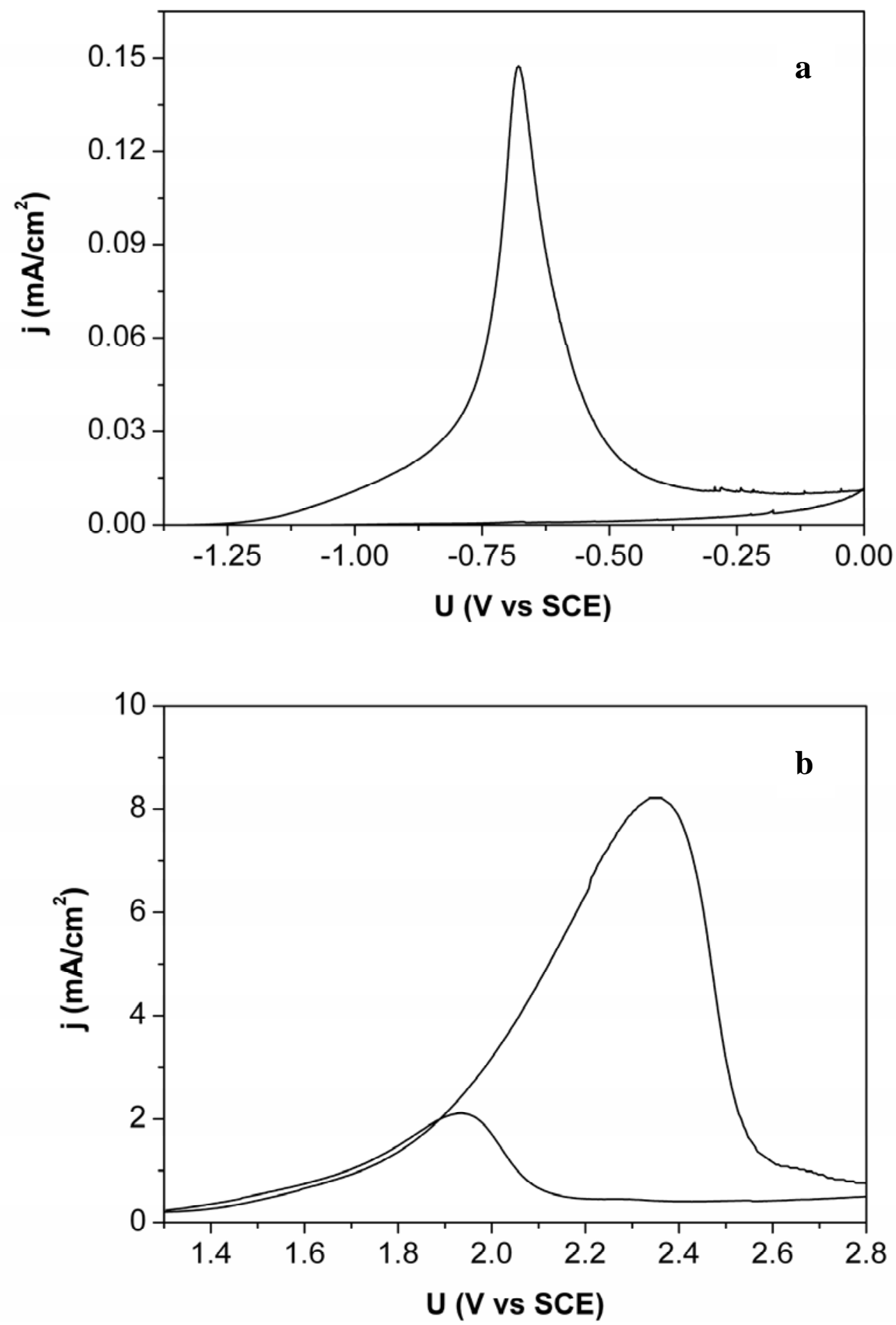

Figure 1. Current density-potential plots recorded for p-type Si and p-type 4H SiC (b) in $0.1 \mathrm{M} \mathrm{KOH}$ solution at $20.5^{\circ} \mathrm{C}$. Both experiments were performed in the dark. 
Figure 1(a) shows a typical current density-potential plot (j-U) for a p-type Si electrode in a $0.1 \mathrm{M} \mathrm{KOH}$ solution. No cathodic current is observed at negative potential: reduction of water to hydrogen requires conduction band electrons. As the potential is scanned to more positive values, a rapidly increasing anodic current is observed and the electrode finally passivates. Because of the presence of oxide on the surface, the current in the return scan is very low (the time required for chemical dissolution of the oxide is long). The j-U curve for p-type $\mathrm{SiC}$ in $0.1 \mathrm{M} \mathrm{KOH}$ solution (fig. 1(b)) shows features similar to those of p-type $\mathrm{Si}$ : an anodic current increasing as the potential is scanned to positive values, followed by passivation. There are two striking differences between the two semiconductors:

(i) - The onset of anodic current for $\mathrm{SiC}(1.4 \mathrm{~V})$ is much more positive than that for $\mathrm{Si}(-$ $1.2 \mathrm{~V})$. This is due to the more positive flat-band potential of the wide-bandgap semiconductor [15]. The valence-band edge of $\mathrm{SiC}$ is at much lower energy than that of $\mathrm{Si}$; consequently, hole injection into $\mathrm{SiC}$ from oxidizing agents in solution (essential for electroless etching) is not possible;

(ii) - The current density required for the passivation of $\mathrm{SiC}$ is a factor of 56 larger than that for $\mathrm{Si}$ at the same potential scan rate. This is very likely due to the presence of $\mathrm{C}$ in the compound semiconductor lattice, making it more difficult to form a protecting oxide.

As in the case of $\mathrm{Si}$, the anodic current for $\mathrm{SiC}$ does not depend on the electrode rotation rate. In both cases the anodic current depends strongly on the $\mathrm{OH}^{-}$ion concentration. This is shown for p-type $\mathrm{SiC}$ in fig. 2(a); the dependence of the anodic peak current density on $\mathrm{OH}^{-}$ion concentration is given in fig. 2(b). From fig. 2(a) it is clear that the hysteresis in the voltammograms due to the passivation is reduced as the $\mathrm{pH}$ is increased; this is due to an increased oxide etch rate. From a comparison of the two semiconductors we conclude that the dissolution rate of the anodic oxide on $\mathrm{SiC}$ is considerably higher than that of the oxide on $\mathrm{Si}$ at the same $\mathrm{pH}$ (the hysteresis for $\mathrm{Si}$ in fig. 1a is more pronounced than that for $\mathrm{SiC}$ in fig. 1b). The peak current densities observed, correspond to etch rates ranging from 105 up to $523 \mathrm{~nm} / \mathrm{min}$ for a concentration span of 0.1-1.0 $\mathrm{M}$ of $\mathrm{KOH}$ (see right axis fig. 2(b)). The "activation energy" calculated from the temperature dependence of the peak current density for $\mathrm{SiC}(46 \mathrm{~kJ} / \mathrm{mol})$ indicates that the anodic reaction is kinetically controlled; this is in agreement with the lack of influence of rotation rate on the current. 

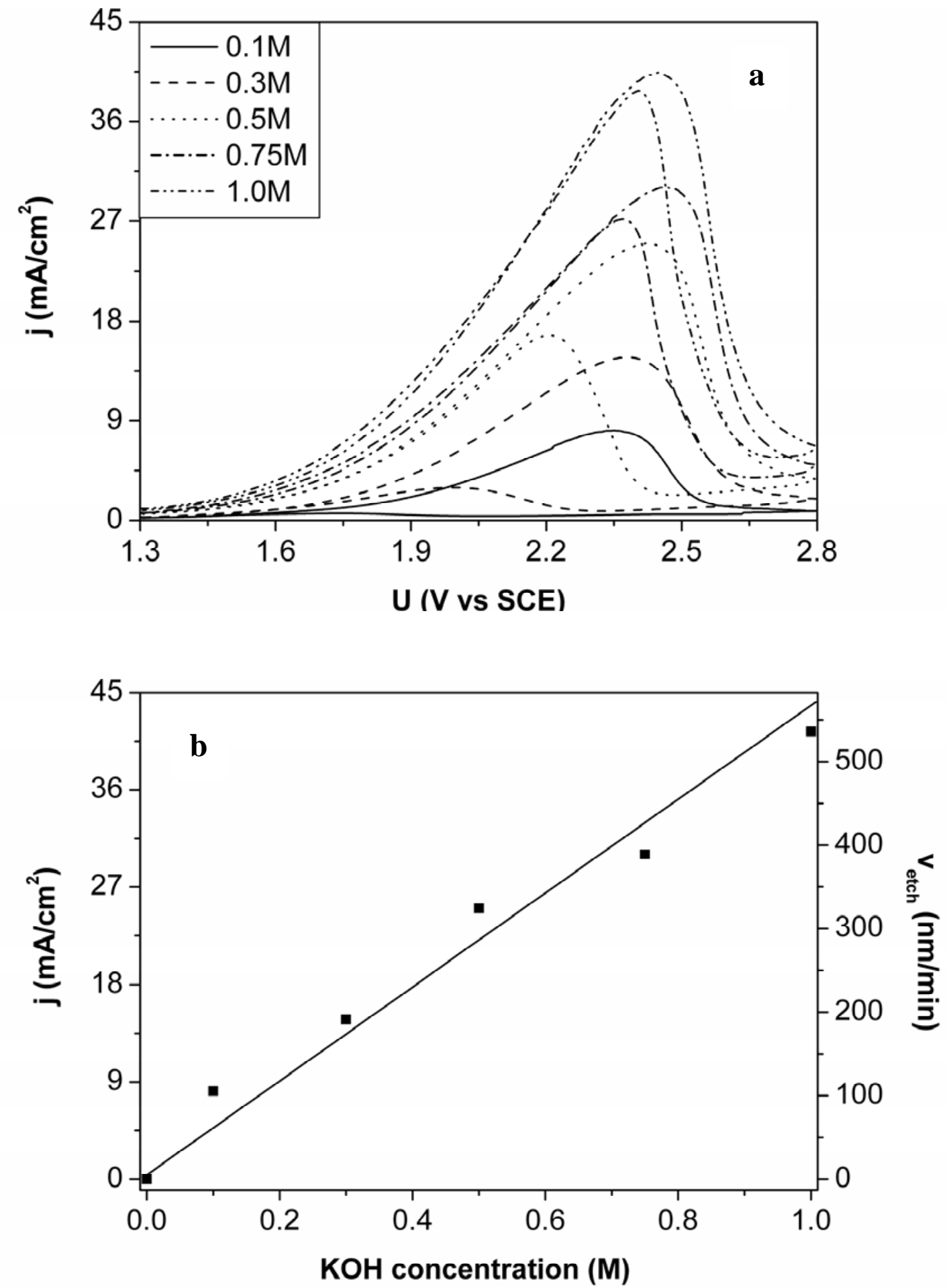

Figure 2. Current-potential curves for $\mathrm{p}$-type $4 \mathrm{H}-\mathrm{SiC}$ at different $\mathrm{KOH}$ concentrations at $20.5^{\circ} \mathrm{C}$ (a). The values of the peak current and the passivation current are plotted against the $\mathrm{KOH}$ concentration (b). The rights axis shows the calculated etch rate. 

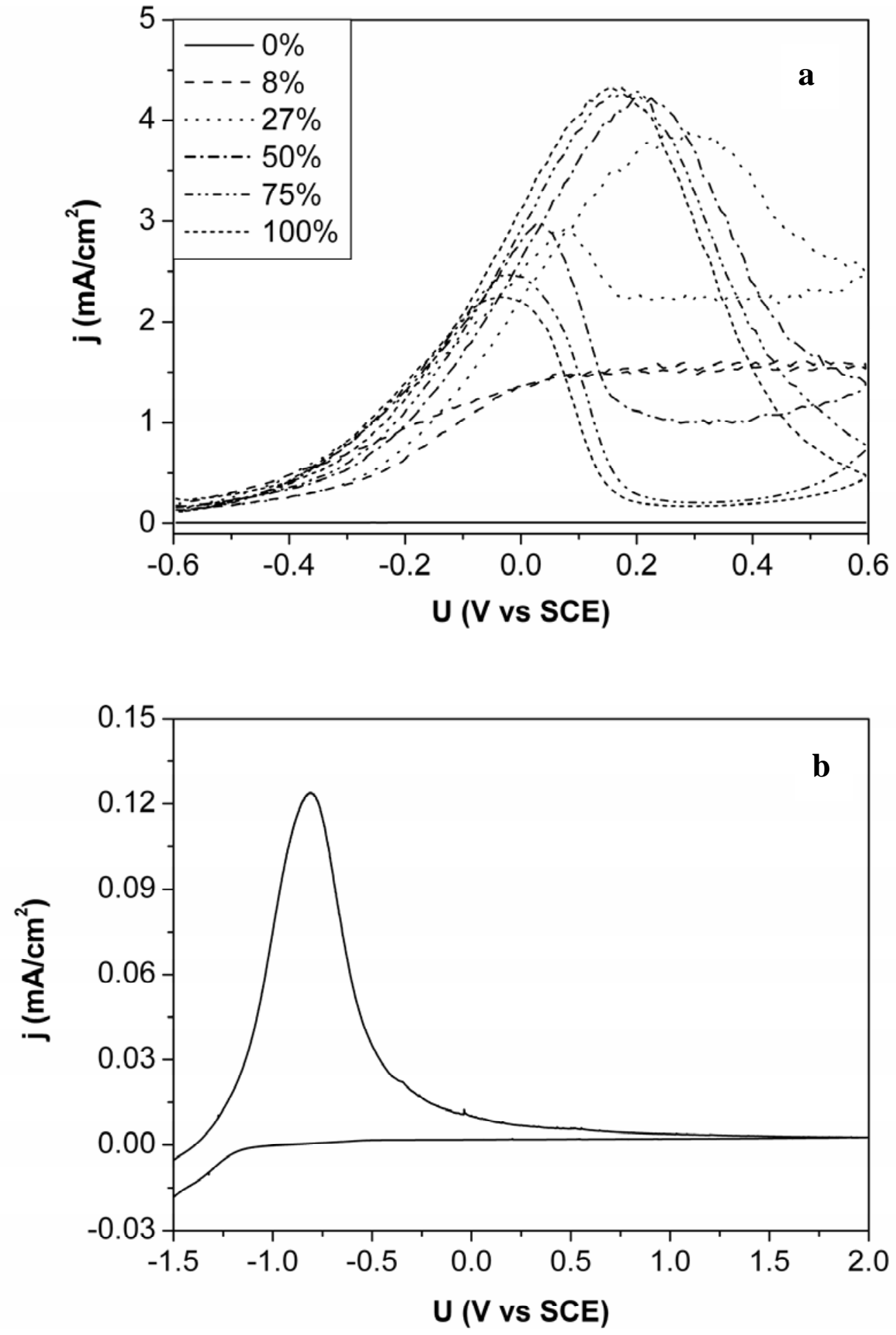

Figure 3. Current density-potential plots recorded for n-type $4 \mathrm{H} \mathrm{SiC}$ at different light intensities (a) and n-type Si in the dark (b) in $0.1 \mathrm{M} \mathrm{KOH}$ solution at $20.5^{\circ} \mathrm{C}$. 
As one expects, n-type $\mathrm{SiC}$ is not anodically oxidized in the dark (fig. 3(a)). Hydrogen evolution gives rise to a cathodic current at negative potential. Under supra-bandgap illumination, anodic photocurrent is observed. At lower light intensity the limiting value is linearly dependent on the photon flux (this is not shown in fig. 3 (a)). At high photon flux the n-type electrode passivates at a current density similar to that required to passivate p-type SiC. Contrary to what we previously reported [18] the peak current density does not increase at higher light intensity [19]. In contrast to $\mathrm{SiC}, \mathrm{n}$-type $\mathrm{Si}$ can be anodically oxidized in the dark, giving rise to unexpectedly high current densities (fig. 3(b)); the current required to passivate $\mathrm{p}$ - and n-type $\mathrm{Si}$ at a given $\mathrm{pH}$ is almost the same (compare figures 1(a) and 3(b). The anodic reaction at n-type Si can be explained on the basis of the chemical etching, which occurs in alkaline solution at the oxide-free surface. Intermediates from this reaction give rise to states in the bandgap, from which electrons can be injected into the conduction band; this process gives an anodic current leading to oxidation and passivation of the electrode [5]. SiC does not etch chemically in aqueous solutions under these conditions.

The dissolution valency for $\mathrm{SiC}$ was determined by measuring simultaneously anodic charge and etch depth at various potentials between current onset and the peak. It was found that between 6 and 7 charge carriers are required to dissolve one formula unit of $\mathrm{SiC}$. A valency of 6 indicates a reaction in which $\mathrm{Si}$ is oxidized to $\mathrm{Si}(\mathrm{IV})$ as silicate species in solution and the $\mathrm{C}$ forms $\mathrm{CO}$ :

$$
\mathrm{SiC}+8 \mathrm{OH}^{-}+6 \mathrm{~h}^{+}(\mathrm{VB}) \rightarrow\left[\mathrm{Si}(\mathrm{OH})_{2} \mathrm{O}_{2}\right]^{2-}+\mathrm{CO}+3 \mathrm{H}_{2} \mathrm{O}
$$

Equation 1 allows us to convert current density to etch rate (see right axis, Fig. 2 (b)). Some $\mathrm{CO}_{2}$ may also be formed accounting for the higher valency. The reaction in the passive range is, very likely, of the form:

$$
\mathrm{SiC}+6 \mathrm{OH}^{-}+6 \mathrm{~h}^{+} \rightarrow \mathrm{SiO}_{2}+\mathrm{CO}+3 \mathrm{H}_{2} \mathrm{O}
$$

The RMS roughness of surfaces etched under these conditions was in the order of 20 $\mathrm{nm}$. This is clearly not the finish required for a polished surface. However, the high etch rates that can be achieved anodically in $\mathrm{KOH}$ solution can be useful for removing damaged surface layers caused by wafer polishing. To follow the effects of photoanodic 
etching of n-type $\mathrm{SiC}$, we measured the electroluminescence of $\mathrm{SiC}$ in acidic solution. A strong oxidizing agent, the peroxydisulphate anion $\left(\mathrm{S}_{2} \mathrm{O}_{8}{ }^{2-}\right)$, was reduced at negative potential. This is a two-step reaction: the first is a conduction-band (CB) step producing the radical anion $\mathrm{SO}_{4}{ }^{-}$; this very strong oxidizing species can subsequently inject a hole into the valence band (VB):

$$
\begin{gathered}
\mathrm{S}_{2} \mathrm{O}_{8}{ }^{2-}+\mathrm{e}^{-}(\mathrm{CB}) \rightarrow \mathrm{SO}_{4}^{-{ }^{-}}+\mathrm{SO}_{4}{ }^{2-} \\
\mathrm{SO}_{4}{ }^{-} \rightarrow \mathrm{SO}_{4}{ }^{2-}+\mathrm{h}^{+}(\mathrm{VB})
\end{gathered}
$$

Electron-hole recombination can give light emission [20]. For the as-received sample a broad emission is found in the visible spectral range (curve (a) fig. (4)); this is very likely due to defect emission (donor-acceptor type). After removal of $10.3 \mu \mathrm{m}$ of material by etching, the spectrum changed quite drastically (curve (b) fig. (4)). The intensity of the broad defect emission decreased and a sharp band with an energy just below the bandgap appeared. This is a clear indication of a favourable change in surface properties due to etching. 


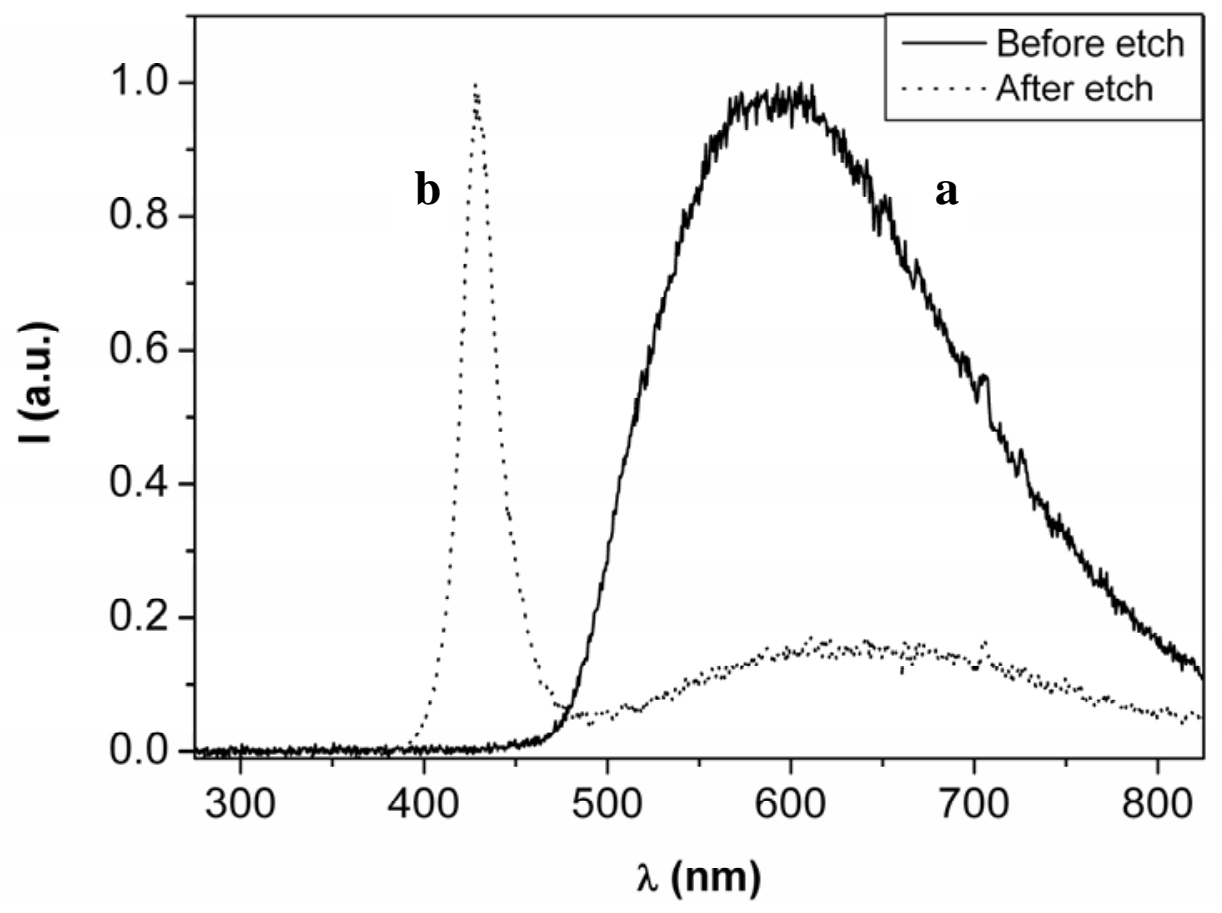

Figure 4. Electroluminescence spectra of n-type $6 \mathrm{H} \mathrm{SiC}$ as received (straight line) and after removal of a $10.3 \mu \mathrm{m}$ thick crystal layer (dotted line). 


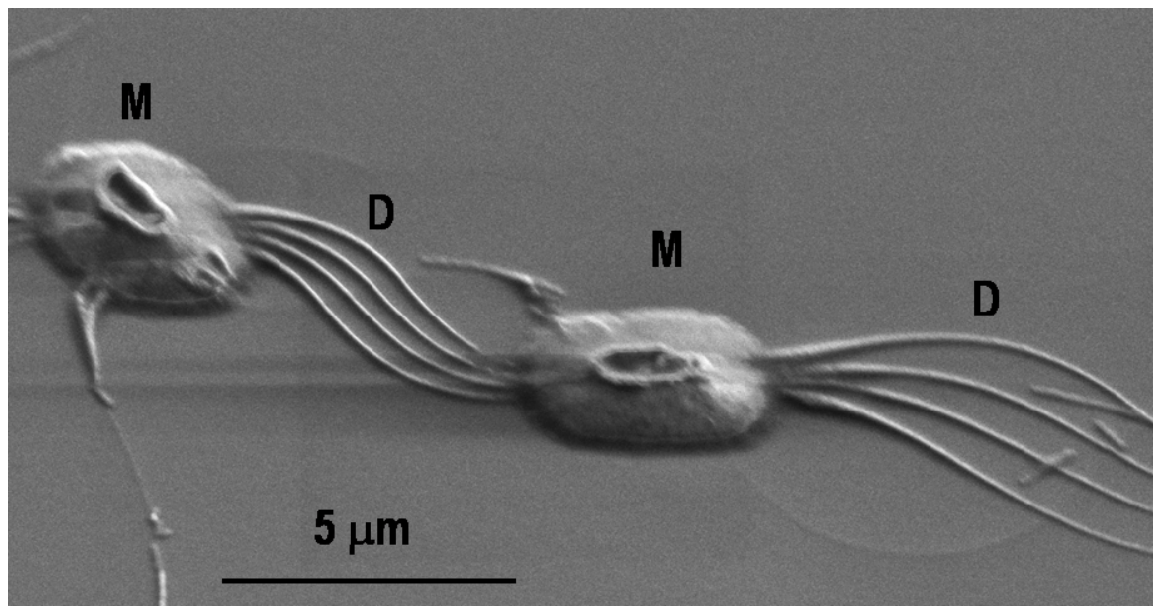

Figure 5. SEM image of etch features formed on micropipes (M) and pinning dislocations (D) parallel to the (0001) Si surface of a SiC substrate revealed by defect selective photoanodic etching.

Photoanodic etching of n-type $\mathrm{SiC}$ can be used not only for removing damage but also for revealing defects. In the lower part of the photocurrent-potential curve, electron-hole recombination competes with the hole reaction (oxidation of the solid). Since crystallographic imperfections act as very effective recombination centers, etching at such defects is (partly) suppressed, giving rise to hillocks (see fig. 5).

The fact that only Si can be etched chemically and that there are considerable differences in the electrochemistry of $\mathrm{Si}$ and $\mathrm{SiC}$, offers a number of options for materialselective etching, interesting for MEMS. These include selective etching of either p-type or n-type $\mathrm{SiC}$ in a p-n junction, and selective etching of $\mathrm{SiC}$ with respect to $\mathrm{Si}$ or vice versa [17]. 
$\underline{\text { Low } \mathrm{pH}}$
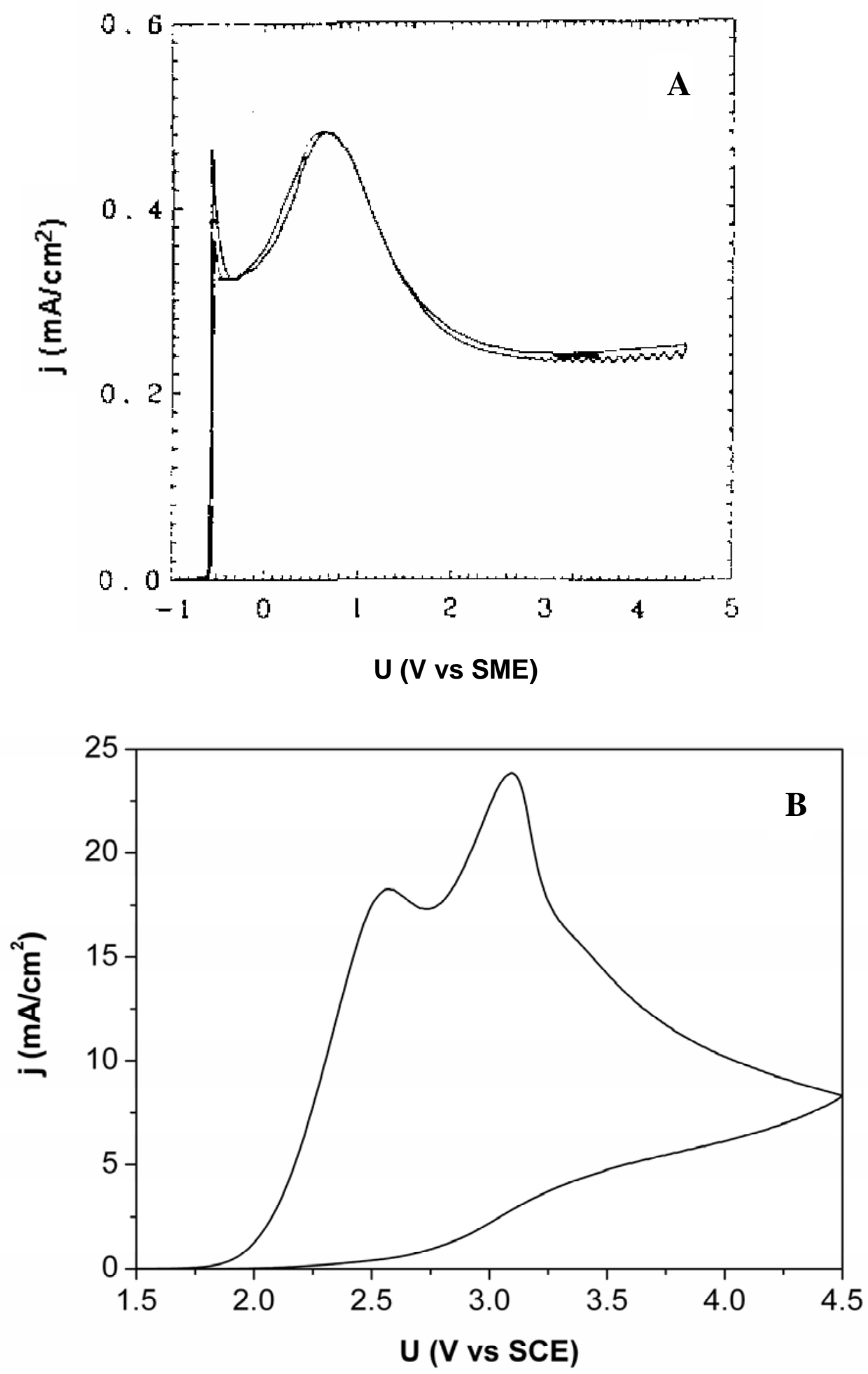

Figure 6. Current density-potential plots recorded in fluoride media $\left(\mathrm{c}_{\mathrm{f}}=33 \mathrm{mM}, \mathrm{pH}=3\right)$ for p-type $\mathrm{Si}$ [21](a) and p-type 4H SiC (b). The rotation rates used were $1600 \mathrm{RPM}$ and $1500 \mathrm{RPM}$ for Si and SiC respectively. Note: In fig 6(a) the potential is given with respect to a saturated mercury/mercurous sulfate (SME) reference electrode. 
For anodic oxidation of $\mathrm{Si}$ in fluoride solution at low $\mathrm{pH}$, valence band holes are essential: p-type Si dissolves in the dark, while illumination is required for the n-type electrode [21-23]. Fig. 6(a) shows results of Hassan et al. for p-type Si at pH 3. In the current onset porous $\mathrm{Si}$ is formed. At more positive potentials, oxide formation gives rise to a number of peaks in the voltammogram (the nature of the oxide depends on the potential). Measurements in this range at different rotation rates showed the anodic reaction to be under mixed transport-kinetic control. In the reverse scan current oscillations and some hysteresis are observed. The current-potential characteristics of ptype $\mathrm{SiC}$ (fig. 6(b)) show features similar to those of p-type Si. The peaks in the voltammogram suggest the formation of soluble oxides.

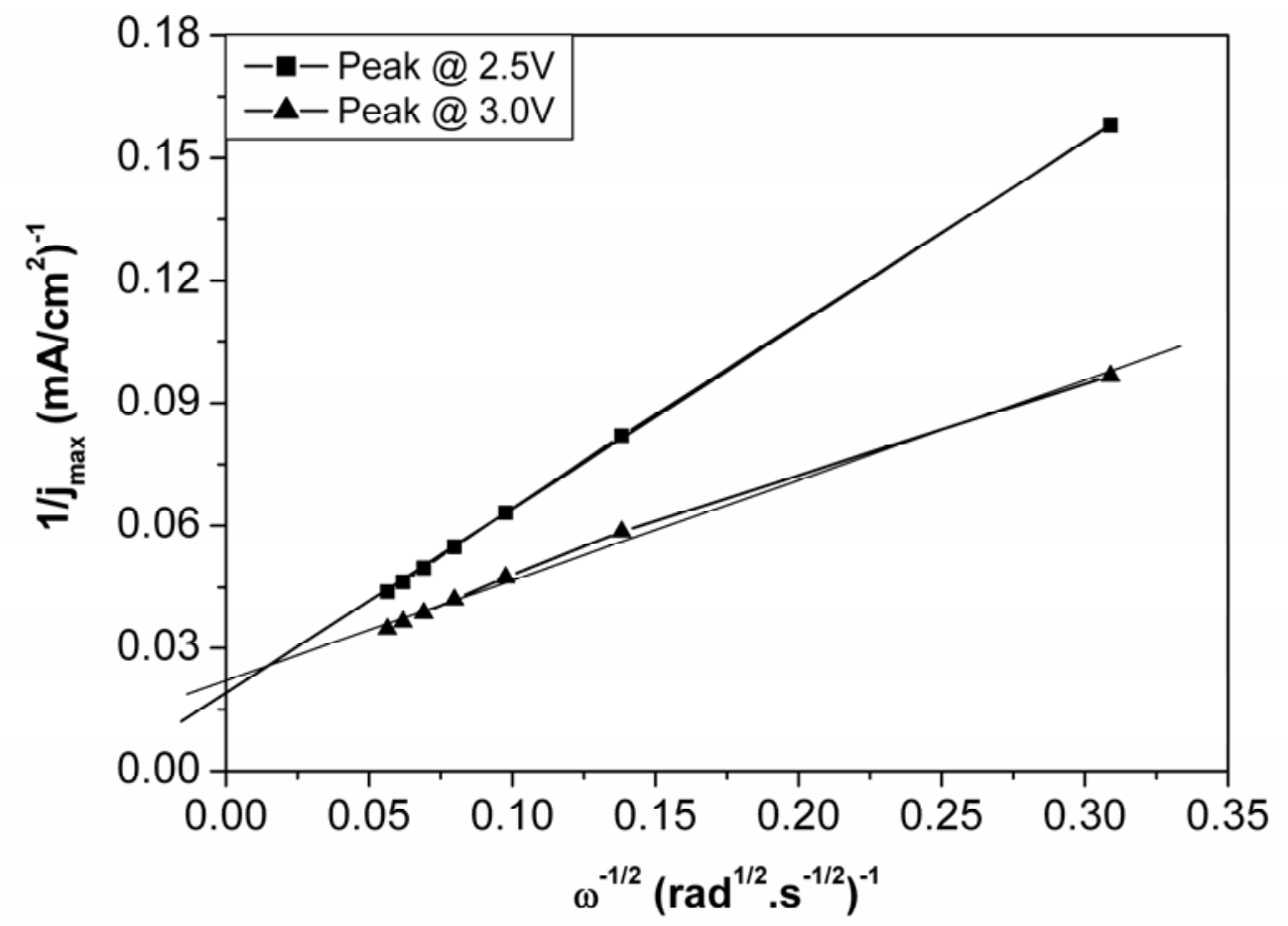

Figure 7. Koutecky-Levich plot based on the measurements performed in a $33 \mathrm{mM}$ fluoride solution. The rotation rates were varied between 100-3000 RPM. 
Fig. 7 shows a Koutecky-Levich analysis [21] of the first and second peaks in the voltammogram: the inverse of the peak current is plotted as a function of the inverse of the square root of the rotation rate. The straight lines with intercept on the y-axis show that, as in the Si case, anodic oxidation is under mixed transport-kinetic control. For both semiconductors the form of the voltammogram depends on the composition of the solution. Two differences observed at high $\mathrm{pH}$ values are also found in fluoride solution: current onset for $\mathrm{p}$-type $\mathrm{SiC}$ is at a markedly more positive potential than for $\mathrm{p}$-type $\mathrm{Si}$ (due to the difference in flat-band potential) and the current required for oxide formation (the first peak) is much higher in the case of SiC. Curiously, a much stronger hysteresis is observed in the $\mathrm{SiC}$ case, suggesting the presence of a more resistive oxide. This is the opposite to what we observe in alkaline solution (fig. 1(b)). In contrast to anodic etching of $\mathrm{SiC}$ at high $\mathrm{pH}$, a much better surface finish can be obtained in the acidic fluoride solutions (an RMS roughness of $5 \mathrm{~nm}$ ). This is perhaps not surprising since it is known that $\mathrm{Si}$ is electropolished under these conditions [24].

\section{Conclusions}

Like $\mathrm{Si}$, both p-type and n-type $\mathrm{SiC}$ undergo anodic oxidation and passivation in $\mathrm{KOH}$ solution. The current-potential characteristics of p-type $\mathrm{SiC}$ resemble those of p-type $\mathrm{Si}$, but much higher current densities are required for passivation of the compound semiconductor. Unlike $\mathrm{Si}, \mathrm{n}$-type $\mathrm{SiC}$ is anodically oxidized and passivated only under supra-bandgap illumination. In acidic fluoride solution both p-type semiconductors show anodic oxidation and, at more positive potentials, non-passivating oxide formation. On the basis of this study we discuss dissolution mechanisms of $\mathrm{SiC}$ in aqueous solution. In addition, we point out a number of applications interesting for $\mathrm{SiC}$ device technology. Furthermore, the electroluminescence of $\mathrm{SiC}$ in acidic peroxydisulphate solution was observed and the effect of photoanodic etching on this process is shown.

\section{Acknowledgements}

The authors would like to thank Ruud Balkenende (Philips Research, The Netherlands), Hans Ligthart and Harold Philipsen for contributing to this work. This work was financially supported by the Dutch Technology Foundation (STW, UPC-6317). 


\section{References}

[1] Seidel H, Csepregi L, Heuberger A, and Baumgartel H, J. Electrochem. Soc. 137 (1990) 3612.

[2] Vellekoop M J, Vanrhijn A J, Lubking G W, and Venema A, Sensors and Actuators a-Physical 27 (1991) 699.

[3] Tirole N, Hauden D, Blind P, Froelicher M, and Gaudriot L, Sensors and Actuators a-Physical 48 (1995) 145.

[4] Faust J W, Jr.; Palik, E D, J. Electrochem. Soc. 130 (1983) 1413.

[5] Xia X H, Ashruf C M A, French P J, Rappich J, and Kelly J J, J. Phys. Chem. B 105 (2001) 5722.

[6] Ashruf C M A, French P J, Bressers P, Sarro P M, and Kelly J J, Sensors and Actuators a-Physical 66 (1998) 284.

[7] Collins S D, J. Electrochem. Soc. 144 (1997) 2242.

[8] Lehmann V, Electrochemistry of Silicon, WILEY-VCH Verlga GmbH, Weinheim, 2002.

[9] Wang S W, Di Ventra M, Kim S G, and Pantelides S T, Phys. Rev. Lett. 86 (2001) 5946.

[10] Di Ventra M and Pantelides S T, Phys. Rev. Lett. 85 (2000) 1782.

[11] Willander M, Friesel M, Wahab Q U, and Straumal B, Journal of Materials Science-Materials in Electronics 17 (2006) 1.

[12] Connolly E J, Timmer B, Pham H T M, Groeneweg J, Sarro P M, Olthuis W, and French P J, Sensors and Actuators B-Chemical 109 (2005) 44.

[13] Sarro P M, Sensors and Actuators a-Physical 82 (2000) 210.

[14] Shor J S, Grimberg I, Weiss B Z, and Kurtz A D, Appl. Phys. Lett. 62 (1993) 2836.

[15] van de Lagemaat J, Vanmaekelbergh D, and Kelly J J, J. Appl. Phys. 83 (1998) 6089.

[16] Okojie R S, Ned A A, and Kurtz A D, Sensors and Actuators a-Physical 66 (1998) 200.

[17] vanDorp D H K, J J; Weyher J L, Journal of Micromechanics and Microengineering in Press (2007) xxx.

[18] vanDorp D H and Kelly J J, J. Electroanal. Chem. 599 (2007) 260.

[19] p. The increase in peak current with increasing light intensity reported in ref. [18] was due to a thermal effect.

[20] Kelly J J, Kooij E S, and Meulenkamp E A, Electrochim. Acta 45 (1999) 561.

[21] Hassan H H, Sculfort J L, Etman M, Ozanam F, and Chazalviel J N, J. Electroanal. Chem. 380 (1995) 55.

[22] Etman M, Neumannspallart M, Chazalviel J N, and Ozanam F, J. Electroanal. Chem. 301 (1991) 259.

[23] Chazalviel J N, Etman M, and Ozanam F, J. Electroanal. Chem. 297 (1991) 533.

[24] Zhang X G, Collins S D, and Smith R L, Journal of the Electrochemical Society 136 (1989) 1561. 